\title{
INDETERMINACY AND STABILITY IN A MODIFIED ROMER MODEL: A GENERAL CASE
}

\author{
Sergey Slobodyan
}
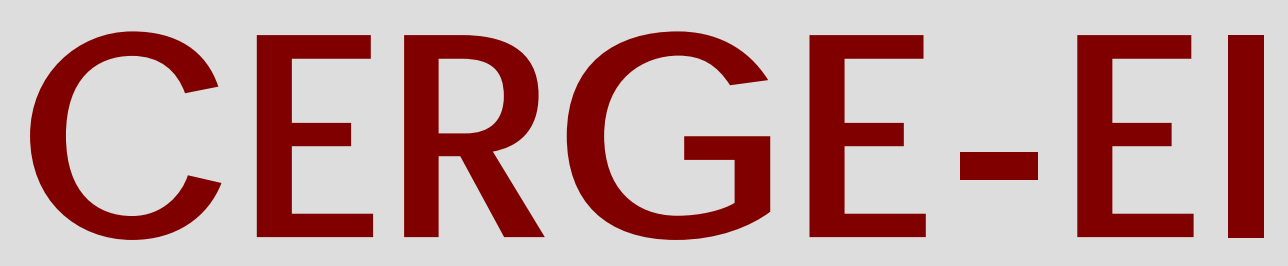

Charles University Centerfor Economic Research and Graduate Education Academy of Sciences of the Czech Republic Ec onomic Institute 


\title{
Working Paper Series $\quad 284$ (ISSN 1211-3298)
}

\section{Indeterminacy and Stability in a Modified Romer Model: A General Case}

\author{
Sergey Slobodyan
}

\author{
CERGE-EI \\ Prague, January 2006
}


ISBN 80-7343-079-7 (Univerzita Karlova v Praze, CERGE)

ISBN 80-7344-068-7 (Národohospodářský ústav AV ČR, Praha) 


\title{
Indeterminacy and Stability in a Modified Romer Model: A General Case
}

\author{
Sergey Slobodyan*
}

$\mathrm{CERGE}-\mathrm{EI} \dagger$

\begin{abstract}
This paper studies the dynamical properties of an extension of the well - known Romer model of endogenous growth introduced by Benhabib, Perli, and Xie (1994). This model differs from the Romer model by introducing complementarity of intermediate capital goods. It allows an indeterminate steady state for relatively mild degrees of the complementarity. We derive necessary and sufficient conditions for the steady state to be interior and strictly positive, which extend those discussed in Benhabib, Perli, and Xie (1994). We show that Hopf bifurcation to the absolutely stable steady state is impossible and that the steady state is determinate if the model parameter values belong to a certain set. For the set of parameter values that allows indeterminacy, we demonstrate the possibility of Hopf bifurcation using both analytical and numerical approaches. The indeterminate steady state can undergo Hopf bifurcation for a wide range of parameter values.
\end{abstract}

\begin{abstract}
Abstrakt
Tato studie zkoumá dynamické vlastnosti rozšíření známého Romerova modelu endogenního růstu poprvé použitého Benhabibem (1994). Tento model se od Romerova liší zavedením komplementarity meziproduktů kapitálových statků. To dovoluje i pro relativně malé stupně komplementarity neurčitost stacionárního stavu ekonomiky. My odvozujeme nutné a postačující podmínky proto, aby stacionární stav byl vnitřním a striktně pozitivním řešením, což rozšiřuje podmínky diskutované Behabibem (1994). Ukazujeme, že Hopfova bifurkace k absolutně stabilnímu stacionárnímu stavu je nemožná a stacionární stav je determinován pokud parametry modelu náleží do určité množiny. Použitím analytických i numerických př́stupů ukazujeme pro množinu hodnot parametrů, které povolují neurčitost, možnost existence Hopfovy bifurkace. Nedeterminovaný stacionární stav může podstoupit Hopfovu bifurkaci pro širokou škálu hodnot parametrů.
\end{abstract}

JEL Classification: E32, O41

Keywords: indeterminacy, stability, Hopf bifurcation, Romer model

\footnotetext{
*Sergey.Slobodyan@cerge-ei.cz. tel. +420 224005 211, fax +420 224227 143. This paper was partially written during a research visit to the Federal Reserve Bank in St. Louis, whose financial support is gratefully acknowledged.

†CERGE-EI is a joint workplace of the Center for Economic Research and Graduate Education, Charles University, and the Economics Institute of the Academy of Sciences of the Czech Republic.

Address: CERGE-EI, P.O. Box 882, Politických věznnu 7, Prague 1, 111 21, Czech Republic.
} 


\section{Introduction}

This paper considers the dynamic properties of a model of endogenous technological change with complementary intermediate capital goods, introduced by Benhabib, Perli, and Xie (1994), henceforth BPX. The BPX model extends the well-known Romer model, (Romer 1990). Uniqueness of the equilibrium trajectory in the Romer model was studied in several papers. Arnold (2000a, 2000b) show that if the simplified Romer model (no unskilled labor) has an interior steady state, then this steady state is locally determinate in both decentralized and centrally planned versions of the model. Necessary and sufficient conditions for the non-existence of complex roots implying oscillatory convergence to the steady state were derived.

BPX introduce complementarity of different intermediate capital goods into the Romer model. They prove that strong enough complementarities might imply an indeterminate steady state, but they do not derive the necessary and sufficient conditions for this; only numeric results are obtained. Asada, Semmler, and Novak (1998) study the stability properties of a social planner version of the Romer model and several modifications of it, including the one introduced by BPX. They also study numerically the eigenvalue structure of the original decentralized BPX model, and find Hopf bifurcation points and stable periodic solutions. Finally, Slobodyan (2002) extends BPX by tightening parameter restrictions necessary to obtain an interior steady state, and studies the stability of the steady state in a simplified BPX model without unskilled labor.

This paper extends previously obtained results on dynamic properties of the steady state in a decentralized BPX model, in particular those of Slobodyan (2002). In Section 2, we present the BXP model as a 3D system of ODE that is slightly simpler to analyze than the one in BPX. We derive further restrictions on parameter values necessary to obtain an interior steady state solution, which are not derived by BPX. This analysis is a streamlined version of that given in Slobodyan (2002). In Section 3, we show that Hopf bifurcation leading from a determinate steady state to a completely stable one does not exist, but that an indeterminate steady state can become absolutely unstable (explosive) through Hopf bifurcation. We derive (analytically and numerically) parameter values of the bifurcation point in the latter case. Such a bifurcation can lead to the appearance of a stable limit cycle 
or explosive behavior.

\section{BPX Model, Interior Solution}

In this Section, we follow BPX in briefly describing the model and deriving the system of ODEs. The economy consists of competitive research and final sectors and a continuum of intermediate good monopolies. The inputs are capital $K$, knowledge $A$, and unskilled $(L)$ and skilled $(H)$ labor. $\eta$ units of the final good produce one unit of an intermediate good. Total capital in the economy is given by $K=\eta \int_{0}^{A} x(i) d i$, where $A$ is the level of knowledge currently available. Final good production technology is given by

$$
Y=h^{\alpha} L^{\beta}\left(\int_{0}^{A} x(i)^{\frac{\gamma}{\xi}} d i\right)^{\xi},
$$

where $\gamma=1-\alpha-\beta$ and $\xi \geq 1$ is the degree of complementarity. In the original Romer model $\xi$ equals onr. $h$ is skilled labor employed in the final sector.

In a symmetric equilibrium, where $x(i)=x$, capital evolves as

$$
\dot{K}=Y-C=\eta^{-\gamma} K^{\gamma} A^{\xi-\gamma} h^{\alpha} L^{\beta}-C .
$$

The final sector firms' demand for intermediate capital goods generates an inverse demand function, $p(j)=\gamma h^{\alpha} L^{\beta}\left(\int_{0}^{A} x(i)^{\frac{\gamma}{\xi}} d i\right)^{\xi-1} x(j)^{\frac{\gamma}{\xi}-1}$. Solving profit maximization problem of monopolies producing intermediate capital goods results in

$$
r=\frac{\gamma^{2} \eta^{-\gamma}}{\xi} K^{\gamma-1} A^{\xi-\gamma} h^{\alpha} L^{\beta}
$$

where $r$ is the interest rate. Comparison with the expression for $p(j)$ gives intermediate firms' profits,

$$
\pi=p(j) x(j)-r \eta x(j)=\frac{\eta(\xi-\gamma)}{\gamma} r x(j) .
$$

The production function in the research sector is given by

$$
\dot{A}=\delta(H-h) A \text {. }
$$

With free entry into the research sector, the price for a new "design" equals the NPV of profits derived from it, $\left.P_{A}(t)=\int_{0}^{\infty} \pi(\tau) \exp \left(-\int_{t}^{\tau} r(s) d s\right)\right) d \tau$, which after differentiating produces

$$
\dot{P}_{A}=r P_{A}-\pi
$$


Equality of skilled labor wage in the research and final sector implies

$$
P_{A}=\frac{\alpha \eta^{-\gamma}}{\delta} K^{\gamma} A^{\xi-\gamma-1} h^{\alpha-1} L^{\beta} .
$$

The maximization problem of the infinitely living representative household with period utility function $U(C)=\frac{C^{1-\sigma}}{1-\sigma}$ gives the last equation of the model,

$$
\frac{\dot{C}}{C}=\frac{r-\rho}{\sigma}
$$

Substituting (2) into (1), introducing the new variable $q=\frac{C}{K}$, and then plugging $K=\eta A x,(6)$, and (3) into (5), we get

$$
\begin{aligned}
\frac{\dot{q}}{q} & =\frac{r-\rho}{\sigma}-\frac{\xi}{\gamma^{2}} r+q, \\
\frac{\dot{K}}{K} & =\frac{\xi}{\gamma^{2}} r-q, \\
\frac{\dot{P_{A}}}{P_{A}} & =r-\frac{\delta \gamma(\xi-\gamma)}{\alpha \xi} h=r-\frac{\delta}{\Lambda} h,
\end{aligned}
$$

where $\Lambda$ is given by $\frac{\alpha \xi}{\gamma(\xi-\gamma)}$. Taking logs in (6) and (2), differentiating with respect to time, equating the former with (10) and substituting (9) into the latter, and solving the resulting equations for $\frac{\dot{r}}{r}$ and $\frac{\dot{h}}{h}$, we get the following system of ODE:

$$
\begin{aligned}
(1-\alpha) \frac{\dot{r}}{r} & =(\xi-1+\beta) \delta(H-h)-\beta\left(\frac{\xi}{\gamma^{2}} r-q\right)-\alpha\left(r-\frac{\delta}{\Lambda} h\right), \\
(1-\alpha) \frac{\dot{h}}{h} & =(\xi-1-\gamma) \delta(H-h)+\gamma\left(\frac{\xi}{\gamma^{2}} r-q\right)-\left(r-\frac{\delta}{\Lambda} h\right), \\
\frac{\dot{q}}{q} & =\frac{r-\rho}{\sigma}-\frac{\xi}{\gamma^{2}} r+q .
\end{aligned}
$$

This system is equivalent to the system of (14)-(16) in BXP, but is easier to analyze because only simple polynomials are present on the right hand side. The only difference from BXP is our variable $r \sim y^{\gamma-1} h^{\alpha} .{ }^{1}$ As long as $y \neq 0, h \neq 0$, $(y, h, q) \rightarrow(r, h, q)$ is a smooth change of variables, which locally preserves topological

\footnotetext{
${ }^{1} A$ does not influence steady state or stability of (11). One thus could drop (4) from further consideration, as is also done in BXP. Steady state in $r, h$, and $q$, combined with constant growth rate of $A$, corresponds to a Balanced Growth Path in original variables of the model, $C, K, A$, and $h$. Note that $\frac{r}{h^{\alpha}}$ is proportional to $K A^{\frac{\xi-\gamma}{\gamma-1}}$ and is thus a pre-determined constant. Therefore, there are only 2 non-predetermined variables: $q$ and $h$.
} 
properties of the flow defined by (14)-(16) in BXP around the hyperbolic fixed point. Therefore, local stability properties of (11) are equivalent to that of (14)-(16) in BXP as long as the fixed point is hyperbolic. ${ }^{2}$

The unique non-zero solution of (11) is given by a triple $\left(h^{*}, r^{*}, q^{*}\right)$, where

$$
\begin{array}{rlrl}
h^{*} & =\frac{\Lambda}{\delta} \frac{\delta H[\sigma(\xi-\gamma)-(\xi-1)]+\rho(1-\gamma)}{\Lambda[\sigma(\xi-\gamma)-(\xi-1)]+(1-\gamma)}, & \\
r^{*} & =\frac{1}{1-\frac{1}{\sigma}}\left[\frac{\delta}{\Lambda} h^{*}-\delta\left(H-h^{*}\right)-\frac{\rho}{\sigma}\right], & \sigma \neq 1 \\
q^{*} & =\left(\frac{\xi}{\gamma^{2}}-\frac{1}{\sigma}\right) r^{*}+\frac{\rho}{\sigma} .
\end{array}
$$

There are several necessary conditions that need to be satisfied. ${ }^{3}$ First, the variables $(r, h, q)$ are by construction positive, therefore the steady state values should be positive. Second, $h^{*}$ should be less than the total amount of the skilled labor, $H$. Third, the household's utility should be finite along the BGP. And fourth, the transversality condition should hold at the steady state. Derivations given in Appendix A allow us to put bounds on the "good" sets in the parameter space. They are tighter than those derived in BPX.

Claim 1 The model parameters belonging to the set $\Theta_{1}$ or $\Theta_{2}$ is a necessary and sufficient condition for the system (11) to have an interior BGP solution along which a household's utility integral converges and the transversality condition holds, where

$$
\begin{aligned}
& \Theta_{1}=\left\{\begin{array}{c}
\delta H[\sigma(\xi-\gamma)-(\xi-1)]+\rho(1-\gamma)<0 \\
\rho>\frac{\delta}{\Lambda} H \\
(1-\sigma)(\xi-\gamma) \delta H-\rho(1-\gamma)(1+\Lambda)>0
\end{array}\right\}, \\
& \Theta_{2}=\left\{\begin{array}{c}
\delta H[\sigma(\xi-\gamma)-(\xi-1)]+\rho(1-\gamma)>0 \\
\rho<\frac{\delta}{\Lambda} H \\
(1-\sigma)(\xi-\gamma) \delta H-\rho(1-\gamma)(1+\Lambda)<0
\end{array}\right\} .
\end{aligned}
$$

\footnotetext{
${ }^{2}$ To be more precise, the flows defined by (14)-(16) in BXP and by (11) here are topologically conjugate in the sense of Katok and Hasselblatt (1995, Definitions 2.2.1 and 2.3.1): two flows $\varphi$ and $\psi$ are topologically conjugate if there exists a homeomorphism $f$ such that $\varphi=f \circ \psi \circ$ $f^{-1}$. $f$ maps orbits of $\varphi$ into orbits of $\psi$. As long as $y \neq 0, h \neq 0$, the change of variables $(y, h, q) \rightarrow(r, h, q)$ mapping orbits of (14)-(16) in BXP into orbits of (11) is a homeomorphism. By the Hartman-Grobman theorem, nonlinear flow is locally topologically conjugate to its linear part in a neighborhood of a hyperbolic fixed point; see, for example, Katok and Hasselblatt (1995, Theorem 6.3.1). Topological conjugacy is transitive. Therefore, both considered flows are locally conjugate to the linear part of one of them in a neighborhood of a hyperbolic fixed point. In particular, indeterminacy of the fixed point with respect to one flow implies indeterminacy with respect to the other, as long as the fixed point is hyperbolic.

${ }^{3}$ The logic of the analysis follows that in Arnold (2000b).
} 
The sets $\Theta_{1}$ and $\Theta_{2}$ have a very simple graphical representation. The three equations defining them are straight lines in $\left(\frac{\rho}{\delta H}, \sigma\right)$ coordinates:

$$
\begin{aligned}
\sigma & =\frac{\xi-1}{\xi-\gamma}-\frac{1-\gamma}{\xi-\gamma} \cdot \frac{\rho}{\delta H}, \\
\frac{\rho}{\delta H} & =\frac{1}{\Lambda}, \\
\sigma & =1-\frac{1-\gamma}{\xi-\gamma}(1+\Lambda) \cdot \frac{\rho}{\delta H} .
\end{aligned}
$$

The set $\Theta_{1}\left(\Theta_{2}\right)$ lies below (above) line (13a), to the right (left) of the (13b), and below (above) line (13c). All three lines intersect in one point, $O=\left(\frac{1}{\Lambda}, \frac{\xi-1-\frac{1-\gamma}{\Lambda}}{\xi-\gamma}\right)$, which is located on the $\sigma$ axis when $\xi-1-\frac{1-\gamma}{\Lambda}=0$. This quadratic in $\xi$ equation has a unique solution $\xi^{*}(\alpha, \gamma)$ for $\xi>1$. When $\xi<\xi^{*}(\alpha, \gamma)$, the point $O$ lies below the $\sigma$ axis, and $\Theta_{1}$ does not contain economically meaningful points with $\sigma>0$. The maximal value of $\sigma$ in $\Theta_{1}$ is given by

$$
\sigma_{\max }=\frac{\xi-1-\frac{1-\gamma}{\Lambda}}{\xi-\gamma}
$$

a function of $\xi, \alpha$, and $\gamma$. The cases $\xi \gtrless \xi^{*}(\alpha, \gamma)$ are presented in Figure 1: (13c) is dashed, and line (13a) solid.

One should note that in the set $\Theta_{1}$ the steady state exhibits some counterintuitive properties. All growth rates in the model are proportional to $\delta\left(H-h^{*}\right)=$ $\frac{(\delta H-\Lambda \rho)(1-\gamma)}{\Lambda \Psi+(1-\gamma)}$. In $\Theta_{1}, \Lambda \Psi+(1-\gamma)<0$, and the model is characterized by an inverse scale effect: growth rates fall as the total amount of skilled labor $H$ increases. Growth rates also fall when $\rho$ decreases (agents become more patient).

\section{Stability of the Steady State}

Complete characterization of the model's dynamics is difficult. We concentrate on Hopf bifurcation - passing of the imaginary axis by two complex conjugate eigenvalues with non-zero speed. The importance of the possibility (or impossibility) of the Hopf bifurcation is clear from the following consideration. Start from a saddle path stable steady state (2 positive, 1 negative eigenvalue). A Hopf bifurcation then means that all the eigenvalues become negative and the steady state is absolutely stable (indeterminate). Any choice of controls selects a trajectory converging to the steady state. On the other hand, if the steady state initially was indeterminate (1 

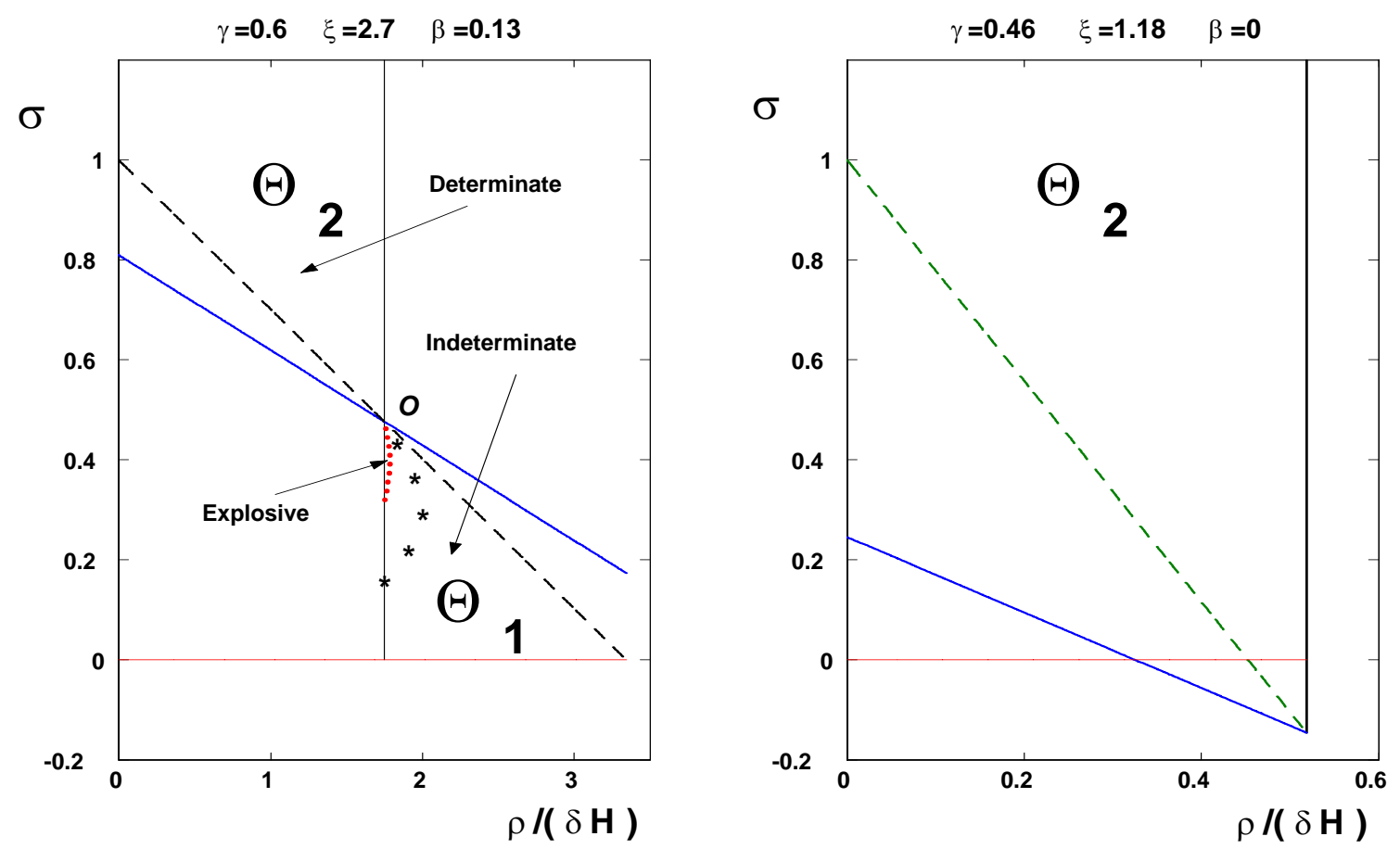

Figure 1: Sets in the parameter space that guarantee interior steady state and finite utility

positive, 2 negative eigenvalues), a Hopf bifurcation creates an absolutely unstable steady state. ${ }^{4}$ We show that in the BXP model the first situation is impossible, while the second could happen for low enough $\beta .^{5}$

Linearize (11) near $\left(r^{*}, h^{*}, q^{*}\right)$ to get the steady state Jacobian:

$$
J^{*}=\left[\begin{array}{ccc}
-\frac{r^{*}}{1-\alpha}\left(\alpha+\beta \frac{\xi}{\gamma^{2}}\right) & \frac{\delta}{1-\alpha} r^{*}\left(\frac{\alpha}{\Lambda}-(\xi-1+\beta)\right) & \frac{\beta}{1-\alpha} r^{*} \\
\frac{1}{1-\alpha} h^{*}\left(\frac{\xi}{\gamma}-1\right) & \frac{\delta}{1-\alpha} h^{*}\left(\frac{1}{\Lambda}-(\xi-1-\gamma)\right) & -\frac{\gamma}{1-\alpha} h^{*} \\
q^{*}\left(\frac{1}{\sigma}-\frac{\xi}{\gamma^{2}}\right) & 0 & q^{*}
\end{array}\right] .
$$

In the discussion below we need expressions for $\operatorname{det}\left(J^{*}\right)$ and $\operatorname{Tr}\left(J^{*}\right)$. The determinant of the steady state Jacobian was calculated in BXP. Rewriting it using this paper's variables, we get

$$
\operatorname{det}\left(J^{*}\right)=-\frac{r^{*} q^{*} \delta h^{*}}{(1-\alpha) \sigma \Lambda}\{\Lambda[\sigma(\xi-\gamma)-(\xi-1)]+1-\gamma\}
$$

\footnotetext{
${ }^{4}$ This might imply either divergent behavior or the existence of a stable limit cycle, in which case the Balanced Growth Path becomes an indeterminate Balanced Growth Cycle. Numerical results in Asada, Semmler, and Novak (1998) indicate that a stable (indeterminate) limit cycle tends to appear.

${ }^{5}$ Slobodyan (2002) considered the case $\beta=0$, in which case Hopf bifurcation creating an unstable steady state is always possible.
} 
The expression in figure brackets is positive (negative) if the model parameters are in $\Theta_{2}\left(\Theta_{1}\right)$ (see Appendix A) and therefore $\operatorname{det}\left(J^{*}\right)<(>) 0$ in $\Theta_{2}\left(\Theta_{1}\right)$. Calculations in Appendix B demonstrate that $\operatorname{trace}\left(J^{*}\right)>0$ in both $\Theta_{1}$ and $\Theta_{2}$.

By the Routh-Hurwitz theorem, the number of positive eigenvalues of a $3 \times 3$ matrix $A$ equals the number of sign changes in

$$
\left(-1, \operatorname{Tr}(A),-B A+\frac{\operatorname{det}(A)}{\operatorname{Tr}(A)}, \operatorname{det}(A)\right)
$$

where $B A$ is the sum of $2^{\text {nd }}$ order minors. See Gantmacher (1960) for the proof.

We consider two special cases: the model parameters belong to $\Theta_{2}$, and specific lines in set $\Theta_{1}$.

\subsection{Set $\Theta_{2}$}

In this case $\operatorname{Tr}\left(J^{*}\right)>0, \operatorname{det}\left(J^{*}\right)<0$, and the sequence of signs becomes $(-,+, ?,-)$. The only possibility is thus 2 positive eigenvalues and 1 negative. The interior steady state is determinate, or saddle path stable, in the whole $\Theta_{2}$.

Claim 2 If the model parameters belong to set $\Theta_{2}$, then the unique interior steady state is determinate. No Hopf bifurcations are possible.

Because the stable manifold is one-dimensional, we can be sure that for initial conditions in a small neighborhood of $\left(r^{*}, h^{*}, q^{*}\right)$ convergence to the steady state of (11) is monotonic. No oscillatory convergence is possible. Using the inverse transformation of variables $(r, h, q) \rightarrow(y, h, q)=\left(\left(r h^{-\alpha}\right)^{\frac{1}{\gamma-1}}, h, q\right)$, one could uniquely determine the values of initial conditions that put the system (14)-(16) in BXP onto the stable manifold.

\subsection{Boundaries of Set $\Theta_{1}$}

When set $\Theta_{1}$ is not empty, its boundaries are given by straight lines (13b), (13c), and $(\sigma=0)$. For low enough $\beta$, there is a Hopf bifurcation point on (13b) which splits this boundary into 2 parts: 1 positive eigenvalue below it, and 3 above it and below the point $O$, where the steady state is not unique. There might exist a bifurcation point on (13c), depending on parameter values. One thus expects a line 
of Hopf bifurcation points, such as the line of stars in Figure 1. This line is likely converge to $O$, which is indeed the behavior confirmed numerically. ${ }^{6}$

In $\Theta_{1}, \operatorname{det}\left(J^{*}\right)>0$, and the sign sequence is $(-,+, ?,+)$. Therefore, $-B A+\frac{\operatorname{det}}{T r}=$ 0 is equivalent to the Hopf bifurcation. When $\frac{\rho}{\delta H}=\frac{1}{\Lambda},(12)$ gives $\left(r^{*}, h^{*}, q^{*}\right)=$ $\left(\rho, H, \frac{\xi}{\gamma^{2}} \rho\right)$. The trace equals $\rho\left(1+\frac{\xi}{\gamma}+\frac{\Lambda}{1-\alpha}\right)>0$, see (25). From (26), we get

$$
B A=\frac{\rho^{2} \xi}{(1-\alpha) \gamma} \times\left\{1+\Lambda-\alpha-\frac{1}{\gamma}\left(\alpha+\frac{1-\alpha-\gamma}{\sigma}\right)\right\} .
$$

Condition $B A=\frac{\text { det }}{T r}$ then implies

$$
\sigma_{H o p f}=\frac{\frac{1-\alpha-\gamma}{\gamma}+\frac{\Lambda(\xi-1)-1+\gamma}{(1-\alpha)(1+\xi / \gamma)+\Lambda}}{1+\Lambda-\alpha-\frac{\alpha}{\gamma}+\frac{\Lambda(\xi-\gamma)}{(1-\alpha)(1+\xi / \gamma)+\Lambda}} .
$$

The unique solution is positive if $\Theta_{1}$ is not empty. ${ }^{7}$ It is easy to show that for $\beta=0$ the solution belongs to $\Theta_{1}$. As $\beta$ increases from zero to some $\beta_{\text {crit }}$, $\sigma_{\text {Hopf }}$ approaches from below and then exceeds $\sigma_{\max }$; thus, there are no Hopf bifurcations in $\Theta_{1}$ for $\beta \geq \beta_{\text {crit }}{ }^{8}$ Equation $\sigma_{\text {Hopf }}=\sigma_{\max }$ is a complicated quadratic equation in $\beta_{\text {crit }}$.

The boundary (13c) might contain Hopf bifurcation points. Calculations in Appendix $\mathrm{C}$ show that in this case $B A$ is given by

$$
\frac{\rho}{1-\sigma} \frac{\delta\left(H-h^{*}\right)(\xi-\gamma)}{(1-\alpha) \gamma}\left[1+\Lambda-\frac{\alpha+\frac{\beta}{\sigma}}{1-\gamma}\left(\frac{\xi}{\gamma}-\gamma\right)\right] .
$$

Therefore, if the term in square brackets is negative, there is no solution and no bifurcation point on (13c) in $\Theta_{1}$. If this term is positive, there might exist a solution that belongs to $\Theta_{1}$. For $\beta=0$, one could show that the condition $(\xi-\gamma) \gamma(1+\gamma)<$ $\xi(\xi-1)$ rules out bifurcation points on $(13 \mathrm{c})$ in $\Theta_{1} \cdot{ }^{9}$

Claim 3 If the model parameters are in $\Theta_{1}$, the positive steady state is either indeterminate or absolutely unstable. The latter case is possible for sufficiently low $\beta$.

\footnotetext{
${ }^{6}$ It is easy to show that there are no bifurcation points at the "external" boundary (13a) or in the neighborhood of $(\sigma=0)$, therefore the bifurcation point line that starts at $(13 \mathrm{~b})$ is likely to end up at $O$. Note that only at (13a) is our change of variables $(y, h, q) \rightarrow(r, h, q)$ not a homeorphism in the neighborhood of a fixed point.

${ }^{7} \sigma_{\max }>0$ implies $\Lambda(\xi-1)-(1-\gamma)>0$, and $1+\Lambda-\alpha-\frac{\alpha}{\gamma}=1-\alpha+\alpha \frac{\gamma}{\xi-\gamma}>0$.

${ }^{8} \sigma_{\text {Hopf }}>\sigma_{\max }$ does not imply presense of a Hopf bifurcation in $\Theta_{2}$, because in this set the condition $B A=\frac{\text { det }}{\text { trace }}$ is not equivalent to the Hopf bifurcation, as shown in Claim 2 .

${ }^{9}$ If $\beta=0$, the condition which guarantees that the set $\Theta_{1}$ is not empty, $\sigma_{\max }>0$ can be written as $(\xi-\gamma) \gamma<\xi(\xi-1)$. Therefore, presence or absence of a bifurcation point on (13c) depends on the values of $\xi$ and $\gamma$, see Slobodyan (2002). For $\beta>0$, the area of $(\xi, \gamma)$ space compatible with Hopf bifurcation point on (13c) shrinks and eventually disappears.
} 


$\begin{array}{ccccccccc}\gamma & \xi & \rho / \delta & \delta, \% & \rho, \% & \sigma & h^{*}, \% & g_{A}, \% & g_{C}, \% \\ 0.6 & 2.7 & 1.752 & 2.279 & 3.993 & 0.319 & 99.81 & 0.004 & 0.023 \\ 0.6 & 2.7 & 1.763 & 2.233 & 3.936 & 0.329 & 98.35 & 0.037 & 0.193 \\ 0.6 & 2.7 & 1.790 & 2.042 & 3.656 & 0.385 & 91.67 & 0.170 & 0.894 \\ 0.6 & 2.7 & 1.785 & 1.960 & 3.499 & 0.419 & 88.37 & 0.228 & 1.196 \\ 0.6 & 2.7 & 1.763 & 1.617 & 3.313 & 0.460 & 84.88 & 0.284 & 1.492\end{array}$

Table 1: Hopf bifurcation boundary $r^{*}=4 \%, S_{K}=25 \%$, parameters in $\Theta_{1}, \beta=\alpha / 2$

Transformation of the indeterminate steady state into the absolutely unstable one occurs through Hopf bifurcation. Hopf bifurcation points exist in the neighborhood of a point of $\Theta_{1}$ where $\frac{\rho}{\delta H}=\frac{1}{\Lambda}$ and $\sigma$ is given by (16). Boundary (13c) might contain bifurcation points if $\beta=0$ and $(\xi-\gamma) \gamma(1+\gamma)>\xi(\xi-1)$.

The above Claim should be understood to make no statement regarding point $O$, where multiple steady states exist, and the simple analysis used in this paper cannot be applied. Note that our analytically constructed example of a Hopf bifurcation corresponds to $h^{*}=H$ and zero growth rates of $A$, consumption, and capital.

\subsection{Hopf Bifurcation Boundary, Numerical Analysis}

A numerical search was conducted in the space $\left(\sigma, \xi, \gamma, \frac{\rho}{\delta H}, \delta\right)$ of the model parameters. Following BXP, we set scaling parameter $H$ equal to 1 , imposed restriction $\beta=\alpha / 2$, fixed the steady state interest rate $r^{*}$ at $4 \%$ and the capital share at $25 \% .{ }^{10}$ To generate numerical results, we selected $\gamma=0.6(0.549)$, which corresponds to $\xi=2.7(2.0)$. The problem of finding the Hopf bifurcation boundary is thus reduced to solving a system of two nonlinear equations ${ }^{11}$ in three variables: $\delta, \rho / \delta$, and $\sigma$. A one-dimensional curve of solutions is plotted as a dotted line in Figure 1. Some of the resulting parameter vectors plus steady state values of $h^{*}$ (share of skilled labor in manufacturing) and growth rates for knowledge and consumption, $g_{A}$ and $g_{C}$, are presented in Table 1.

Note the following features of our results. First, no Hopf bifurcation exists when $\xi=2\left(\beta=0.15\right.$ exceeds $\left.\beta_{\text {crit }}\right)$. For $\xi=2.7$, the locus of Hopf bifurcation points in $\left(\frac{\rho}{\delta H}, \sigma\right)$ space contains two branches, one starting on $(13 \mathrm{~b})$, another projecting from

\footnotetext{
${ }^{10}$ Share of capital $S_{K}$ equals $\frac{\gamma^{2} / \xi}{1-\gamma+\gamma^{2} / \xi}$. Fixing it imposes a functional dependence between $\xi$ and $\gamma$.

${ }^{11} r^{*}=0.04$ and $B A=\frac{\operatorname{det}\left(J^{*}\right)}{\operatorname{trace}\left(J^{*}\right)}$.
} 
$O$, as suggested previously. The two branches merge, creating a compact region where the steady state is absolutely unstable, but this region is very small. Second, the upper branch has reasonable growth rates, with consumption growing at 1.2 to 1.5 percent and $10 \div 15 \%$ of human capital allocated to production of a final good (note that all unskilled labor is used to produce the final good). Third, for relatively high values of $\sigma$ close to $\sigma_{\max }$ we observe both indeterminate and explosive steady state.

\section{Conclusion}

This paper contains two contributions. First, we provided necessary and sufficient conditions on the model parameters ( Romer model, described by BPX, has an interior positive steady state with finite lifetime utility of the representative consumer. The steady state in $\Theta_{1}$ demonstrates an inverse scale effect: growth rate of the economy falls as its size increases. Growth rate also falls as agents become more patient.

Second, we studied stability of the steady state in the BPX model. The steady state is determinate in $\Theta_{2}$. We calculated $\sigma_{\max }$, the maximum value of $\sigma$ which is compatible with $\Theta_{1}$ and the indeterminate steady state. The indeterminate steady state in $\Theta_{1}$ can become absolutely unstable through Hopf bifurcation if unskilled labor is not too important ( $\beta$ is low). We analytically derived coordinates of the Hopf bifurcation point in one special case ${ }^{12}$ and characterized the form of the bifurcation boundary, which separates the "indeterminate" subset of $\Theta_{1}$ from the "absolutely unstable" one. Finally, we numerically constructed the Hopf bifurcation boundary.

Both indeterminacy and absolute instability require rather high values of intertemporal elasticity of substitution of consumption. The other parameter values and implied growth rates necessary to generate either of these stability regimes are reasonable.

\footnotetext{
${ }^{12}$ This special case is not intended to be realistic: as all human capital is spent in R\&D, there is no growth.
} 


\section{References}

Arnold, L. G. (2000a): "Endogenous Technological Change: A Note on Stability," Economic Theory, 16, 219-226.

Arnold, L. G. (2000b): "Stability of the Market Equilibrium in Romer's Model of Endogenous Technological Change: A Complete Characterization," Journal of Macroeconomics, 22, 69-84.

Asada, T., W. Semmler, And A. J. Novak (1998): "Endogenous Growth and the Balanced Growth Equilibrium," Research in Economics, 52, 189-212.

Benhabib, J., R. Perli, and D. XIE (1994): "Monopolistic Competition, Indeterminacy and Growth," Ricerche Economiche, 48, 279-298.

Gantmacher, F. R. (1960): The Theory of Matrices. Chelsea, New York.

Katok, A., And B. Hasselblatt (1995): Introduction to the Modern Theory of Dynamical Systems. Cambridge University Press, Cambridge.

Romer, P. M. (1990): "Endogenous Technological Change," Journal of Political Economy, 98, S71-S103.

Slobodyan, S. (2002): "Indeterminacy and Stability in a Modified Romer Model," CERGE-EI WP 205.

\section{A Sets $\Theta_{1}$ and $\Theta_{2}$.}

Consider constraints $h^{*}>0$ and $H-h^{*}>0$. Denote $\Psi=[\sigma(\xi-\gamma)-(\xi-1)]$. Given that $h^{*}=\frac{\Lambda}{\delta} \frac{\delta H \Psi+\rho(1-\gamma)}{\Lambda \Psi+(1-\gamma)}, \delta\left(H-h^{*}\right)=\frac{(\delta H-\Lambda \rho)(1-\gamma)}{\Lambda \Psi+(1-\gamma)}$, and $\Lambda$ is a positive number, one of the two cases must be true:

$$
\begin{array}{ccc}
\delta H \Psi+\rho(1-\gamma)<0, & \delta H \Psi+\rho(1-\gamma)>0 \\
\Theta_{1}: \quad \Lambda \Psi+(1-\gamma)<0, & \text { or } \quad \Theta_{2}: & \Lambda \Psi+(1-\gamma)>0 \\
\rho>\frac{\delta}{\Lambda} H . & & \rho<\frac{\delta}{\Lambda} H .
\end{array}
$$

If $\Psi>0$, then $\delta H-\Lambda \rho>0$ satisfies both $h^{*}>0$ and $H-h^{*}>0$. Positive $\Psi$ is thus observed only in $\Theta_{2}$. Consider now negative $\Psi$. In the $\Theta_{1}$ case, $1^{\text {st }}$ and $3^{\text {rd }}$ lines of (17) imply the $2^{n d}: 0>\delta H \Psi+\rho(1-\gamma)>\frac{\delta H}{\Lambda}[\Lambda \Psi+(1-\gamma)]$. Similarly, 
in $\Theta_{2}, \Lambda \Psi+(1-\gamma)>0$ is satisfied automatically given $1^{\text {st }}$ and $3^{\text {rd }}$ lines are true: $0<\delta H \Psi+\rho(1-\gamma)<\rho[\Lambda \Psi+(1-\gamma)]$. Dropping $2^{\text {nd }}$ lines of (17) gives the sets of model parameters $\Theta_{1}$ and $\Theta_{2}$ (equivalent to those derived by BPX) which guarantee that $h^{*}>0$ and $H-h^{*}>0$ :

$$
\begin{aligned}
\Theta_{1} & =\left\{\delta H[\sigma(\xi-\gamma)-(\xi-1)]+\rho(1-\gamma)<0 \text { and } \rho>\frac{\delta}{\Lambda} H\right\} \\
\Theta_{2} & =\left\{\delta H[\sigma(\xi-\gamma)-(\xi-1)]+\rho(1-\gamma)>0 \text { and } \rho<\frac{\delta}{\Lambda} H\right\} .
\end{aligned}
$$

Consider now $r^{*}$. Along the BGP, $r, h$, and $q$ are constant, and $A$ grows with rate $\delta\left(H-h^{*}\right)$. Interest rate $r$ is proportional to $K^{\gamma-1} A^{\xi-\gamma}$, therefore the capital growth rate is given by $\delta\left(H-h^{*}\right) \frac{\xi-\gamma}{1-\gamma}$. Constancy of $q=\frac{C}{K}$ means that $C$ grows with the same rate as $K, g_{C}^{*}=\delta\left(H-h^{*}\right) \frac{\xi-\gamma}{1-\gamma}$. (7) then implies $r^{*}=\rho+\sigma g_{C}^{*}>0$ as long as $g_{C}^{*} \geq 0$, which is satisfied in sets $\Theta_{1}$ and $\Theta_{2}$ together with their boundaries.

The next step is to ensure that the household utility remains finite. The utility is given by $U=\int_{0}^{\infty} \frac{C^{1-\sigma}}{1-\sigma} \exp (-\rho t) d t$. Given $g_{C}^{*}=\delta\left(H-h^{*}\right) \frac{\xi-\gamma}{1-\gamma}$, the following condition ensures convergence:

$$
(1-\sigma) \delta\left(H-h^{*}\right) \frac{\xi-\gamma}{1-\gamma}-\rho<0
$$

When the model parameters are in $\left\{\Theta_{1}, \Theta_{2}\right\}$ and $\sigma \geq 1$, (18) is trivially satisfied. However, it provides an additional constraint on the model parameters when $\sigma<1$ : after substitution of (12a) into (18) and simplifying, we obtain

$$
\frac{(1-\sigma)(\xi-\gamma) \delta H-\rho(1-\gamma)(1+\Lambda)}{\Lambda \Psi+(1-\gamma)}<0
$$

Finiteness of the utility integral also implies that $\lim _{t \rightarrow \infty} C^{-\sigma} K \exp (-\rho t)=0$ (the transversality condition holds), as both $C$ and $K$ grow at the same rate, and TVC is thus equivalent to $(1-\sigma) \delta\left(H-h^{*}\right) \frac{\xi-\gamma}{1-\gamma}-\rho<0$ which is exactly (18).

Finally, we have to check the positivity of $q^{*}=\left(\xi / \gamma^{2}-\frac{1}{\sigma}\right) r^{*}+\frac{\rho}{\sigma}$. If $\xi / \gamma^{2}-\frac{1}{\sigma}>0$, $r^{*}>0$ implies $q^{*}$ is positive. If $\xi / \gamma^{2}-\frac{1}{\sigma}<0$ (this is possible if $\sigma<1$ ), use (23) and (18) to get

$q^{*}=\frac{\xi \rho}{\gamma^{2}}-\frac{\xi / \gamma^{2}-\frac{1}{\sigma}}{1-\frac{1}{\sigma}}(1-\sigma) \delta\left(H-h^{*}\right) \frac{\xi-\gamma}{1-\gamma}>\frac{1-\sigma}{\sigma} \delta\left(H-h^{*}\right) \frac{\xi-\gamma}{1-\gamma} \cdot \frac{\xi / \gamma^{2}-1}{\frac{1}{\sigma}-1}>0$. 


\section{B Calculation of trace}

Trace of (11) is given by

$$
-\frac{\alpha+\beta \xi / \gamma^{2}}{1-\alpha} r^{*}+\frac{\delta}{1-\alpha} h^{*}(1 / \Lambda-(\xi-1-\gamma))+q^{*}
$$

Rewrite (12a) and (12b) as

$$
\begin{aligned}
\frac{\delta}{\Lambda} h^{*} & =\delta\left(H-h^{*}\right) \frac{[\sigma(\xi-\gamma)-(\xi-1)]}{1-\gamma}+\rho \\
r^{*} & =\frac{1}{1-\frac{1}{\sigma}}\left[\rho\left(1-\frac{1}{\sigma}\right)+\delta\left(H-h^{*}\right)\left(\frac{\Psi}{1-\gamma}-1\right)\right] .
\end{aligned}
$$

Plug (22), (23) and (20) into the expression for trace and collect the terms at $\rho$ and $\delta\left(H-h^{*}\right)$ to get

$$
\begin{aligned}
& \rho\left[\frac{\xi / \gamma}{1-\alpha}-\frac{\Lambda(\xi-1-\gamma)-1}{1-\alpha}-\frac{\alpha}{1-\alpha}\right]+\delta\left(H-h^{*}\right) \times \\
& \left\{\begin{array}{c}
(1 / \Lambda-(\xi-1-\gamma)) \frac{\Psi \Lambda}{(1-\alpha)(1-\gamma)}-\frac{\xi / \gamma^{2}-1 / \sigma}{1-1 / \sigma}(1-\sigma) \frac{\xi-\gamma}{1-\gamma}- \\
-\frac{\alpha+\beta \xi / \gamma^{2}}{(1-\alpha)(1-\gamma)} \frac{1}{1-1 / \sigma}(\Psi-(1-\gamma))
\end{array}\right\} .
\end{aligned}
$$

Recalling that $\Lambda=\frac{\alpha \xi}{\gamma(\xi-\gamma)}$, the coefficient multiplying $\rho$ can be simplified to $\xi / \gamma+$ $\Lambda /(1-\alpha)+1$. Replacing $\Psi$ with $\sigma(\xi-\gamma)-(\xi-1)$, the sum of the last two terms in the figure brackets above is given by $-\sigma \frac{\xi-\gamma}{1-\gamma}\left(\frac{1}{\sigma}+\frac{\alpha-\xi / \gamma}{1-\alpha}\right)$. Summing with the first term, one gets

$$
\begin{aligned}
& \frac{1}{(1-\alpha)(1-\gamma)} \times\left\{\Psi\left(\Lambda+1-\frac{\alpha \xi}{\gamma}\right)-\sigma(\xi-\gamma)\left[\frac{1-\alpha}{\sigma}+\alpha-\frac{\xi}{\gamma}\right]\right\} \\
= & \frac{1}{(1-\alpha)(1-\gamma)} \times\left\{\begin{array}{c}
\Psi\left[\Lambda+(1-\alpha)\left(1+\frac{\xi}{\gamma}\right)\right]+(\xi-1)\left(\frac{\xi}{\gamma}-\alpha\right)- \\
(\xi-\gamma)(1-\alpha)
\end{array}\right\} .
\end{aligned}
$$

Expression for $\operatorname{trace}\left(J^{*}\right)$ thus becomes

$$
\rho\left(\frac{\xi}{\gamma}+\frac{\Lambda}{1-\alpha}+1\right)+\frac{\delta\left(H-h^{*}\right)}{(1-\alpha)(1-\gamma)}\left\{\begin{array}{c}
\Psi\left[\Lambda+(1-\alpha)\left(1+\frac{\xi}{\gamma}\right)\right]+ \\
(\xi-1)\left(\frac{\xi}{\gamma}-\alpha\right)-(\xi-\gamma)(1-\alpha)
\end{array}\right\} .
$$

Note that the first term is strictly positive for $\rho>0$, and $\frac{\delta\left(H-h^{*}\right)}{(1-\alpha)(1-\gamma)} \geq 0$. Consider the expression in figure brackets for $\sigma \geq 1$. At $\sigma=1$, it is positive:

$$
\begin{aligned}
&(1-\alpha)\left[(1-\gamma)\left(1+\frac{\xi}{\gamma}\right)-(\xi-\gamma)\right]+(1-\gamma) \Lambda+(\xi-1)\left(\frac{\xi}{\gamma}-\alpha\right)> \\
&(1-\alpha)\left(1+\xi\left(\frac{1}{\gamma}-1\right)\right)>0 .
\end{aligned}
$$


It increases in $\sigma$ : its derivative w.r.t. $\sigma$ equals $(\xi-\gamma)[\Lambda+(1-\alpha)(1+\xi / \gamma)]>0$. The whole $\operatorname{trace}\left(J^{*}\right)$ is thus positive.

Consider now the case $\sigma<1$. In this case (18) is not moot for the interior steady state, and $\rho>(1-\sigma) \delta\left(H-h^{*}\right) \frac{\xi-\gamma}{1-\gamma}$. Substitute this inequality into (25) and after simplification obtain

$$
\begin{aligned}
\operatorname{trace}\left(J^{*}\right)> & \frac{\delta\left(H-h^{*}\right)}{(1-\alpha)(1-\gamma)}\left\{\begin{array}{c}
(1-\sigma)(\xi-\gamma)\left[\left(1+\frac{\xi}{\gamma}\right)(1-\alpha)+\Lambda\right]+ \\
\Psi\left[\Lambda+(1-\alpha)\left(1+\frac{\xi}{\gamma}\right)\right]+ \\
(\xi-1)\left(\frac{\xi}{\gamma}-\alpha\right)-(\xi-\gamma)(1-\alpha)
\end{array}\right\} \\
& =\frac{\delta\left(H-h^{*}\right)}{(1-\alpha)(1-\gamma)}\left\{\begin{array}{c}
(\xi-\gamma)\left(\Lambda+\frac{\xi}{\gamma}-\alpha \frac{\xi}{\gamma}\right)+ \\
(\xi-1)\left(-1-\Lambda+\alpha \frac{\xi}{\gamma}\right.
\end{array}\right\} \\
& =\frac{\delta\left(H-h^{*}\right)}{\gamma(1-\gamma)}\left\{\left[\xi-\gamma+\alpha(1-\gamma)\left(\frac{1}{\xi-\gamma}-1\right)\right] \frac{\xi}{\gamma}-(\xi-1)\right\} .
\end{aligned}
$$

The expression in square brackets in the last line is always positive: it is greater than $\xi-1+\alpha(1-\gamma) /(\xi-\gamma)$. Therefore, the expression in figure brackets is greater than $\left[\xi-\gamma+\alpha(1-\gamma)\left(\frac{1}{\xi-\gamma}-1\right)\right]-(\xi-1)=(1-\gamma)\left[1+\alpha\left(\frac{1}{\xi-\gamma}-1\right)\right]>0$. As a result, $\operatorname{trace}\left(J^{*}\right)>0$ when $\sigma<1$, and thus everywhere in the interior steady state, whenever the parameters are in set $\Theta_{1}$ or $\Theta_{2}$.

\section{Calculation of $B A$}

The sum of $2^{\text {nd }}$ order minors of (14) can be written as

$$
B A=\left\{\begin{array}{c}
-\frac{\delta h^{*}}{\Lambda} \frac{r^{*}}{(1-\alpha)^{2}} \frac{\xi}{\gamma} \frac{1-\alpha}{\gamma}[1-\gamma(1-\alpha)-\Lambda(\xi-1)]+ \\
+\frac{q^{*}}{1-\alpha}\left\{\frac{\delta h^{*}}{\Lambda}[1-\Lambda(\xi-1-\gamma)]-r^{*}\left(\alpha+\frac{\beta}{\sigma}\right)\right\}
\end{array}\right\}
$$

At line (13a), (18) holds with equality. (12) then gives $\frac{\delta h^{*}}{\Lambda}=\delta\left(H-h^{*}\right), r^{*}=\frac{\rho}{1-\sigma}=$ $\delta\left(H-h^{*}\right) \frac{\xi-\gamma}{1-\gamma}$, and $q^{*}=\frac{\xi / \gamma^{2}-1}{1-\sigma} \rho$. The second line becomes

$$
\frac{q^{*}}{1-\alpha} \delta\left(H-h^{*}\right)\left\{1-\Lambda(\xi-1-\gamma)-\frac{\xi-\gamma}{1-\gamma}\left(\alpha+\frac{\beta}{\sigma}\right)\right\} .
$$


Combining the first and the second line, one gets

$$
\begin{aligned}
B A= & -\frac{\delta\left(H-h^{*}\right)}{1-\alpha} \frac{\rho}{1-\sigma} \frac{\xi}{\gamma^{2}}[1-\gamma(1-\alpha)-\Lambda(\xi-1)]+ \\
& +\frac{\xi / \gamma^{2}-1}{1-\sigma} \frac{\rho}{1-\alpha} \delta\left(H-h^{*}\right)\left[1-\Lambda(\xi-1-\gamma)-\frac{\xi-\gamma}{1-\gamma}\left(\alpha+\frac{\beta}{\sigma}\right)\right] \\
= & \frac{\delta\left(H-h^{*}\right)}{1-\alpha} \frac{\rho}{1-\sigma}\left\{\begin{array}{c}
\Lambda(\xi-\gamma)-(1+\Lambda)+\frac{\xi-\gamma}{1-\gamma}\left(\alpha+\frac{\beta}{\sigma}\right)+ \\
+\frac{\xi}{\gamma^{2}}\left[\left(\gamma \Lambda+\gamma(1-\alpha)-\frac{\xi-\gamma}{1-\gamma}\left(\alpha+\frac{\beta}{\sigma}\right)\right)\right]
\end{array}\right\}= \\
= & \frac{\delta\left(H-h^{*}\right)}{(1-\alpha) \gamma} \frac{\rho}{1-\sigma}\left\{(1+\Lambda)(\xi-\gamma)-\frac{\xi-\gamma}{1-\gamma}\left(\alpha+\frac{\beta}{\sigma}\right)\left(\frac{\xi}{\gamma}-\gamma\right)\right\} .
\end{aligned}
$$


Individual researchers, as well as the on-line and printed versions of the CERGE-EI Working Papers (including their dissemination) were supported from the following institutional grants:

- Economic Aspects of EU and EMU Entry [Ekonomické aspekty vstupu do Evropské unie a Evropské měnové unie], No. AVOZ70850503, (2005-2010);

- Economic Impact of European Integration on the Czech Republic [Ekonomické dopady evropské integrace na ČR], No. MSM0021620846, (2005-2011);

Specific research support and/or other grants the researchers/publications benefited from are acknowledged at the beginning of the Paper.

(c) Sergey Slobodyan, 2006

All rights reserved. No part of this publication may be reproduced, stored in a retrieval system or transmitted in any form or by any means, electronic, mechanical or photocopying, recording, or otherwise without the prior permission of the publisher.

Published by

Charles University in Prague, Center for Economic Research and Graduate Education (CERGE) and

Economics Institute (EI), Academy of Sciences of the Czech Republic

CERGE-El, Politických vězñu 7, 11121 Prague 1, tel.: +420 224005 153, Czech Republic.

Printed by CERGE-EI, Prague

Subscription: CERGE-El homepage: http://www.cerge-ei.cz

Editors: Directors of CERGE and EI

Managing editors: Deputy Directors for Research of CERGE and EI

ISSN 1211-3298

ISBN 80-7343-079-7 (Univerzita Karlova v Praze, CERGE)

ISBN 80-7344-068-7 (Národohospodářský ústav AV ČR, Praha) 
CERGE-EI

P.O.BOX 882

Politických vězňů 7

11121 Praha 1

Czech Republic http://www.cerge-ei.cz 